\title{
Anaesthetic Management of a Patient with Necrotizing Fasciitis: A Case Report
}

\author{
Shallu Chaudhary ${ }^{1}$, Major Amit Atwal ${ }^{2}$ \\ ${ }^{1}$ Medical Officer, Health \& Family Welfare Department, Himachal Pradesh, India \\ ${ }^{2}$ Medical Officer, Military Hospital Jutogh Cantt, Shimla, Himachal Pradesh, India \\ Corresponding Author: Major Amit Atwal
}

\begin{abstract}
Necrotizing fasciitis is a highly lethal bacterial infection of subcutaneous tissue and fascia. 77 year old male patient, smoker with necrotizing fasciitis underwent surgery:- left shoulder disarticulation in emergency OT under general anesthesia. Intraoperatively, the patient went into severe sepsis and developed arrythmias and hypotension which were managed with antiarrythmic drugs and infusion norepinephrine. The patient responded to the treatment and the surgery was completed. Postoperatively mechanical ventilation was continued and subsequently the patient improved and was extubated 3 days later.
\end{abstract}

Keywords: Necrotizing fasciitis, necrotizing acute soft tissue injury, NASTI

\section{INTRODUCTION}

Necrotizing fasciitis also known as necrotizing acute soft tissue injury (NASTI), Fournier's gangrene, or flesh eating bacteria is a progressive, often polymicrobial bacterial infection of the fascia and surrounding soft tissue ${ }^{1}$. Most common infectious organism responsible is group $\mathrm{A}$ streptococcus. It spreads rapidly along fascial planes and if left untreated is nearly uniformly fatal $^{2}$. Mortality rate ranges between $30 \%-50 \%{ }^{3}$. It can result in serious complications:- acute respiratory distress syndrome, acute renal failure, cardiac failure, concomitant nosocomial infections, sepsis $^{3}$.

\section{CASE REPORT}

77 year old male patient presented in the OPD with complaint of thorn prick injury in left hand three days back, which was followed by pain and swelling with blackish discoloration of left upper limb. On examination, there was blackish discoloration with unhealthy underlying muscles, limb was cold and left radial and brachial pulses were absent. Clinical diagnosis of necrotizing fasciitis was made.

The patient was put on following treatment:- injection tetanus toxoid IM stat, injection linezolid $600 \mathrm{mg}$ IV BD, injection Metrogyl 500 mg IV TDS, injection PCM 1 gm IV TDS, injection Pantop 40 mg IV OD, injection vitamin K $10 \mathrm{mg}$ IV OD. The patient was scheduled for left shoulder disarticulation in emergency OT.

On Pre anaesthesia checkup: patient was a smoker for last 25 years, vitals:- heart rate- 98/minute, BP- 104/60 $\mathrm{mmHg}$, respiratory rate - 14/minute, temperature- afebrile, GCS-15/15, cardiovascular system - normal S1S2, respiratory system- normal vesicular sounds heard, ECG - revealed ventricular ectopics in long lead 2. On investigations, $\mathrm{Hb}-13.5$ gm, platelet- 1.56 lakh, TLC- 8 thousand, RFT's \& serum electrolytes- WNL, LFT's WNL, ABG analysis:- Ph- 7.417, Po2-62.8, pCO2- 24, SPO2- 91.6, bicarconate- 15.1.

The case was done under general anaesthesia. Premedication was done with injection glycopyrolate $0.2 \mathrm{mg} \mathrm{IV}$, injection fentanyl 100 microgram IV, injection 
ondansetron $4 \mathrm{mg} \mathrm{IV}$, injection loxicard 100 mg IV. Induction was done with injection ketamine $80 \mathrm{mg}+$ injection propofol $30 \mathrm{mg}$ IV. Using rapid sequence induction with Injection succinylcholine under direct laryngoscopy, cuffed endotracheal tube of $7.5 \mathrm{~mm}$ internal diameter was inserted. Injection atracurium $25 \mathrm{mg}$ IV stat was then given. Isoflurane was used for maintenance of anesthesia. The surgery was then started.

15 minutes later, supraventricular tachycardia was observed on ECG. The vitals were:- heart rate- 160/minute, BP102/60 mmHg, SPO2- 98\%. Injection esmolol $10 \mathrm{mg}$ IV stat given. The next vital readings were:- heart rate- $98 /$ minute, BP$80 / 42 \mathrm{mmHg}$, SPO2- 98\%. Injection Nor adrenaline @ 0.05 microgram $/ \mathrm{kg} /$ minute was started.

After about 20 minutes, the ECG started showing paroxysmal supraventricular tachycardia (PSVT). The vitals were as following:- heart rate$163 /$ minute, BP- $118 / 78 \mathrm{mmHg}$, SPO2$98 \%$. Injection adenosine $12 \mathrm{mg}$ IV stat was given. The ECG rhythm reverted back to sinus tachycardia with vitals:- heart rate$130 /$ minute, BP- $120 / 78 \mathrm{mmHg}$, SPO2$98 \%$.

Again 10 minutes later, the ECG started showing ventricular tachycardia. The vitals were as following:- heart rate$170 /$ minute, BP- $128 / 82 \mathrm{mmHg}$, SPO2$98 \%$. The patient was given injection amiodarone $150 \mathrm{mg}$ IV over 10 minutes followed by $1 \mathrm{mg} / \mathrm{minute}$ for 6 hours. The ECG rhythm reverted back to sinus rhythm with vitals:- heart rate- $115 /$ minute, BP108/72 mmHg, SPO2- 99\%. The arterial blood gas (ABG) analysis revealed metabolic acidosis with following values :pH- 7.258, PCO2-35.4, PO2-132.2, HCO216.5, SPO2- 97\%, lactate- 2.29 The surgery was continued and was finished within 45 minutes.

The patient was shifted to ICU postoperatively for further management. The vitals were as following:- heart rate115/minute, BP- 108/72mmHg, SPO2-99\%, GCS-E1VTM1， ECG revealing atrial fibrillation. Bed side ECHO was done which showed normal RV/LV systolic function, no evidence of pericardial effusion. Injection metoprolol $2.5 \mathrm{mg} \mathrm{IV}$ TDS, injection lomoh $0.6 \mathrm{mg}$ S/C OD were added. The ECG reverted to sinus rhythm later and the GCS improved spontaneously. The patient was later extubated on the third day and was shifted to the ward with stable vitals.

\section{DISCUSSION}

Necrotizing fasciitis occurs commonly in patients with diabetes, alcoholism, smoker, IV drug abuser, immunosuppression, local tissue trauma. In our case report, 77 year old patient, smoker presented with necrotizing fasciitis after thorn prick injury.

Early diagnosis, fluid resuscitation, appropriate antibiotic therapy, surgical debridement within few hours of presentation is life saving ${ }^{4}$. Clinical symptoms are variable, usually presents with pain and redness progressing rapidly. In necrotizing fasciitis patients, the combined effect of sepsis, anaesthesia, intravascular volume loss, bleeding and surgical stress results in unstable cardiovascular status and septic shock. In our patient clinical deterioration was very fast and patient landed up in sepsis induced arrhythmias intraoperatively.

Early goal directed resuscitation within the first 6 hours help in reducing the mortality of patients with sepsis and septic shock $^{5}$. Invasive monitoring should be considered in patients with comorbid conditions ${ }^{6}$. Central venous pressure should be restored to $8-12 \mathrm{mmHg}$. Unfortunately this was lacking in our patient. Inadequate perfusion should be corrected with normal saline or ringer lactate. Lack of response to IV fluids necessitates use of vasopressors. Surviving sepsis guidelines 2012 recommend norepinephrine as first choice vasopressor $^{7}$, followed by dopamine and dobutamine. In our patient also, we used infusion of norepinephrine to treat hypotension. 
Under anaesthetic management, the induction techniques are ketamine, etomidate and propofol using small doses of IV anaesthetic agents, titrated to clinical response. In our patient, we used ketamine (80mg) and propofol(30mg). ketamine was preferred due to its good haemodynamic properties. A modified rapid sequence induction using rocuronium rather than succinylcholine to facilitate tracheal intubation may be required. However in our patient, we have used succinylcholine. Among inhalational agents, sevoflurane is the agent of choice and MAC is reduced in severe sepsis ${ }^{8}$. In our case report, we have used isoflurane.

Our patient intraoperatively developed sepsis resulting in haemodynamic instability and arrhythmias. There is a greater likelihood of various cardiac arrhythmias in patients having moderate to severe sepsis ${ }^{9}$. Cardiac arrhythmias could be promoted through the effects of inflammatory mediators. Exotoxins, such as streptolysin $\mathrm{O}$ or pneumolysin with cardiotoxic potential, could induce septic cardiomyopathy into arrythmias ${ }^{10}$.

Most of the patients had atrial fibrillation and could be cardioverted electrically. Supraventricular tachycardia might be cardioverted by vagal manoeuvres similar to carotid sinus massage. In our case report, the patient had supraventricular tachycardia (SVT) initially which was treated with esmolol. Later patient developed paroxysmal supraventricular tachycardia (PSVT) for which injection adenosine had to be administered. A few minutes later, ventricular tachycardia was observed for which anti-arrythmic drug amiodarone was administered and the patient was managed. Post-operatively mechanical ventilation is often continued in persistent haemodynamic instability or according to arterial blood gas obtained. Our patient was also shifted to ICU postoperatively on mechanical ventilation and was later weaned off and extubated.

\section{CONCLUSION}

Patients with necrotizing fasciitis developing severe sepsis often require surgery for source of infection control. Patients suffering worse sepsis have higher risk of atrial and ventricular arrhythmias. Active identification of arrhythmias and treating with antiarrythmic drugs and cardioversion as required is beneficial. Adherence to published guidelines for the management of severe sepsis patients is known to lower mortality. The anaesthetist has an important role in patient survival outcome. In the above case, despite the intraoperative complications we managed to save the patient. Therefore it is believed that strict adherence to current recommendations may improve the chances of survival.

\section{Acknowledgement: None}

\section{Conflict of Interest: None}

\section{Source of Funding: None}

\section{REFERENCES}

1. Tsoa H. Arthritis and musculoskeletal and skin disease. In: Freed-berg IM, Eisen AZ, Wolff K, Goldsmith LA, Katz SI, Fitzpatrick TB, eds. Fitzpatrick's Dermatology in General Medicine. $5^{\text {th }}$ ed. New York, NY: McGraw-Hill; 1999:22132231.

2. Nomikos IN. Necrotizing perineal infections (Fournier's disease): old remedies for an old disease. Int J Colorectal Dis. 1998;13:48-51.

3. Eissa D, Carton EG, Buggy DJ. Anaesthetic management of patients with severe sepsis. Br J Anaesth. 2010;105(6):734-43.

4. Baluch A, Janoo A, Lam K, Hoover J, Kaye A. Septic shock: review and anaesthetic considerations. MEJ Anesth. 2007;19(1):7186.

5. Rivers E, Nguyen B, Havstad S, Ressler J, Muzzin A, Knoblich B, et al. Early goal directed therapy in the treatment of severe sepsis and septic shock. N Engl J Med. 2001;345:1368-77.

6. Stoelting R, Dierdorf S. Early goal-directed resuscitation. In: Stoelting R, Dierdorf S, eds. Anaesthesia and Co-existing Disease. 
$4^{\text {th }}$ ed. London: Churchill Livingstone; 2002: 571-584.

7. Surviving sepsis campaign. Guidelines, 2012. Available at: www.survivingsepsis.org/guidelines.

8. Allaouchiche B, Duflo F, Tournadre JP, Debon R, Chassard D. Influence of sepsis on sevoflurane minimum alveolar concentration in a porcine model. $\mathrm{Br} \mathrm{J}$ Anaesth. 2001;86:832-6.

9. Go AS, Hylek EM, Phillips KA, Chang Y, et al. 2003. Prevalence of Diagnosed Atrial Fibrillation in adults. JAMA.
10. Sato R, Nasu M. 2015. A review of sepsis induced cardiomyopathy. Journal of Intensive Care.

How to cite this article: Chaudhary S, Atwal MA. Anaesthetic management of a patient with necrotizing fasciitis: a case report. International Journal of Science \& Healthcare Research. 2021; 6(3): 31-34. DOI: https://doi.org/10. 52403/ijshr.20210706 